Check for updates

Cite this: J. Mater. Chem. A, 2017, 5 , 20505

\title{
Correction: Biomass-derived interconnected carbon nanoring electrochemical capacitors with high performance in both strongly acidic and alkaline electrolytes
}

\author{
Xianjun Wei, ${ }^{*}$ Yongbin Li and Shuyan Gao* \\ Correction for 'Biomass-derived interconnected carbon nanoring electrochemical capacitors with high \\ performance in both strongly acidic and alkaline electrolytes' by Xianjun Wei et al., J. Mater. Chem. A, 2017, \\ 5, 181-188.
}

www.rsc.org/MaterialsA

The authors regret that eqn (3) in the published article is incorrect. The equation should appear as follows:

$$
E=\frac{0.125 V^{2} C_{1}}{3.6}
$$

As a result of this error, the calculated values for energy density and power density are also incorrect. The values for energy density and power density given in the article should appear as follows:

\begin{abstract}
“... and a high energy density of 12.9-6.0 $\mathrm{W} \mathrm{h} \mathrm{kg}^{-1}$ with a power density of 124.8-6534.0 $\mathrm{W} \mathrm{kg}^{-1}$ in $1 \mathrm{~mol} \mathrm{~L}^{-1} \mathrm{H}_{2} \mathrm{SO}_{4}$ aqueous electrolyte. In $6 \mathrm{~mol} \mathrm{~L}^{-1} \mathrm{KOH}$ electrolyte, they still exhibit high specific capacitances of $350.0 \mathrm{~F} \mathrm{~g}^{-1}\left(1 \mathrm{~A} \mathrm{~g}^{-1}\right)$ and $_{246.9 \mathrm{~F} \mathrm{~g}^{-1}}$ $\left(30 \mathrm{~A} \mathrm{~g}^{-1}\right)$, excellent cycling stability (95.06\% and 91.1\% of capacitance retention after $1000\left(1 \mathrm{~A} \mathrm{~g}^{-1}\right)$ and $10000\left(30 \mathrm{~A} \mathrm{~g}^{-1}\right) \mathrm{cycles}$, respectively), a high energy density of $12.3 \mathrm{~W} \mathrm{~h} \mathrm{~kg}^{-1}$ and a power density of $6459.0 \mathrm{~W} \mathrm{~kg}^{-1}$."
\end{abstract}

\section{Introduction}

(page 2, left hand column, $2^{\text {nd }}$ paragraph)

"Until now... high energy densities $\left(12.9 \mathrm{~W} \mathrm{~h} \mathrm{~kg}^{-1}\right.$ and $\left.12.3 \mathrm{~W} \mathrm{~h} \mathrm{~kg}^{-1}\right)$ and high power densities $\left(6534.0 \mathrm{~W} \mathrm{~kg}{ }^{-1}\right.$ and $\left.6459.0 \mathrm{~W} \mathrm{~kg}{ }^{-1}\right)$ in $1 \mathrm{~mol} \mathrm{~L}^{-1} \mathrm{H}_{2} \mathrm{SO}_{4}$ and $6 \mathrm{~mol} \mathrm{~L}^{-1} \mathrm{KOH}$, respectively."

\section{Results and discussion}

(page 5 , right hand column, $1^{\text {st }}$ paragraph)

"The TDICN-based capacitor presents energy densities of 12.9-6.0 $\mathrm{W} \mathrm{h} \mathrm{kg}{ }^{-1}$ at power densities of $124.8-6534.0 \mathrm{~W} \mathrm{~kg}{ }^{-1} \ldots$.."

(page 5, right hand column, $2^{\text {nd }}$ paragraph)

“The Ragone plot (the inset of Fig. 4B) shows energy densities of 12.3-5.4 $\mathrm{W} \mathrm{h} \mathrm{kg}^{-1}$ at power densities of $124.5-6459.0 \mathrm{~W} \mathrm{~kg}{ }^{-1} \ldots$ ”

\section{Conclusions}

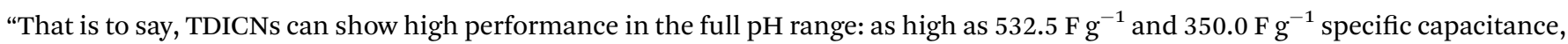

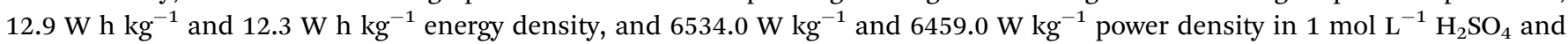
$6 \mathrm{~mol} \mathrm{~L}{ }^{-1} \mathrm{KOH}$. Such a supercapacitor with high power density up to $12.9 \mathrm{~W} \mathrm{~h} \mathrm{~kg}^{-1}$ has enough energy to power some electronic equipment such as a commercial pedometer."

Additionally, on page 2, right hand column, last line, the sentence "And 1.03 is obtained in our case, suggesting a weakly ordered graphitic microstructure with a relatively good electronic conductivity" should read "And 1.03 is obtained in our case, suggesting some graphitic domains rather than an ordered graphitic microstructure with a relatively good electronic conductivity".

Finally, in the ESI, Table S1 has been updated to show the corrected values of power density $(P)$ and energy density $(E)$ for the TDICN samples reported in the article (final 4 entries).

The Royal Society of Chemistry apologises for these errors and any consequent inconvenience to authors and readers. 